\title{
Increase in retention of a taste aversion by weanling rats after a long interval
}

\author{
PHILIPP J. KRAEMER, NANCY A. LARIVIERE, and NORMAN E. SPEAR \\ State University of New York at Binghamton, Binghamton, New York
}

\begin{abstract}
Weanling rats were tested for retention of an aversion to a novel flavor (chocolate milk) that had been conditioned as a single-element conditioned stimulus (CS) or in compound with a novel ambient odor (banana). The presence of the ambient odor during conditioning had no effect on flavor aversion shortly thereafter, confirming previous results. The flavor aversion observed 21 days after conditioning, however, was significantly stronger for pups conditioned with the singleelement CS than for those given the flavor-odor compound as the CS. This retention effect was due to a surprising increase in the conditioned aversion observed 21 days after conditioning with the single-element CS. A second experiment confirmed this paradoxical increase in retention of the aversion to chocolate milk. This experiment also verified that no such increase occurred in retention of the conditioned aversion to a different flavor (saccharin), whether the initial aversion was strong or weak. The results may be explained in terms of generalized latent inhibition from consumption of mother's milk.
\end{abstract}

The initial purpose of the present study was further ontogenetic investigation of the forgetting of conditioned stimulus (CS) elements that had appeared originally in compound with other elements. There are several reasons why such an investigation is useful. First, the effects of stimulus compounding, such as overshadowing and potentiation, may be manifestations of memory retrieval, rather than memory storage; if so, the effects may change with changes in variables likely to alter memory retrieval, such as length of retention interval (Kasprow, Cacheiro, Balaz, \& Miller, 1982; Kaufman \& Bolles, 1981; Spear, 1981). Second, studying the forgetting of elements presented in compound will add to our knowledge of the role of interference in forgetting-in this case, simultaneous interference, rather than retroactive or proactive interference. Third, we may expect age-related differences in the effects of stimulus compounding because of the greater susceptibility of infant rats to forgetting in general, their apparently age-specific disposition to be affected by other elements in a stimulus compound (e.g., Spear, 1984), and their apparently greater susceptibility to interference in retention (e.g., Smith \& Spear, 1981). A test of these differences will help us understand how agespecific dispositions for forgetting and stimulus selection might interact.

In the course of conducting this investigation, we were surprised to discover what may be an ecologically determined instance of latent inhibition-impaired expression of conditioning to milk as a CS among recently weaned animals. This was a transient effect that was alleviated

The authors would like to thank Norman G. Richter and Teri Tanenhaus for their assistance. The present research was supported by a grant from the National Institute of Mental Health (1 RO1 MH35219) to Norman E. Spear. Address correspondence to Norman E. Spear, Center for Developmental Psychobiology, Department of Psychology, SUNY Binghamton, Binghamton, NY 13901. after a relatively long retention interval, similar to the experimentally induced latent inhibition effect observed in adults by Kraemer and Roberts (1984) and in infants by Kraemer, Hoffmann, and Spear (1988). Both phenomena may be related to more general effects of memory retrieval on compound conditioning. In the present study, therefore, we considered the convergence of several issues in basic conditioning and the ontogeny of learning and memory.

\section{EXPERIMENT 1}

In this experiment, the intention was to assess in two respects the generality of the results with weanling rats reported by Kraemer, Lariviere, and Spear (1988). First, we asked whether the effects of compounding an odor with taste CS would change over long retention intervals. Because there were no significant effects of such compounding shortly after conditioning, the effect of a longer interval could be determined with clarity. Second, a two-bottle preference test was used to permit a measure of relative preference to supplement that of absolute intake. The preference index provides a more meaningful comparison of intake over an interval in which the pups' growth led to substantial increase in absolute amounts consumed.

\section{Method}

Subjects. Sixty weanling ( $n=12)$ Sprague-Dawley rats, of both sexes, served as subjects. They were group-housed in plastic maternity cages when weaned on Postnatal Day 19, and were conditioned on Postnatal Day 21. The pups were housed in a climate-controlled vivarium; they were maintained on a 16 -h on/8-h off light/dark cycle and tested during the light portion of the cycle. They were placed on a 23.5-h water-deprivation schedule when weaned on Postnatal Day 19 , and the next day were given a single drinking adaptation session in which they were allowed 30 min access to tap water in the test room. 
Apparatus. Conditioning and testing occurred in wire-mesh hanging cages, located in a room away from the vivarium. Liquids were dispensed at room temperature in graduated cylinders fitted with metal spouts, which were attached to the front of each test cage. The taste stimulus consisted of a $50 \%$ (v/v) solution of homogenized chocolate milk and water. The odorant consisted of $2 \mathrm{cc}$ of banana extract (Virginia Dare) placed on sheets of paper below each test cage. A ventilation fan and air duct filtered odors from the test room. Animals in the taste-alone groups were conditioned before the odorant was added to the room for the conditioning of the compoundstimulus groups.

Design and Procedure. The rats were randomly assigned to three groups according to their conditioning treatments on Postnatal Day 21: Group T (taste $+\mathrm{LiCl}$ ), Group OT (odor-taste $+\mathrm{LiCl}$ ), and Group $C$ (control; taste + saline). Half of the animals in each group at each age were tested after a 1-day interval, and the remaining animals were tested after a 21-day interval.

On the conditioning day, subjects in Group T received $30 \mathrm{~min}$ exposure to the taste followed immediately by a $1 \%$ body-weight i.p. injection of . $3 \mathrm{M} \mathrm{LiCl}$; subjects in Group OT were given $30 \mathrm{~min}$ exposure to an odor-taste compound followed by injection of $\mathrm{LiCl}$; and subjects in Group $\mathrm{C}$ received the taste paired with injection of $.89 \% \mathrm{NaCl}$. The animals were returned to their home cages immediately following injection of $\mathrm{LiCl}$ or saline.

Testing involved $30 \mathrm{~min}$ exposure to two bottles, one containing tap water and the other chocolate milk. The left/right spatial arrangement of the bottles was varied randomly across subjects. The dependent measure was the percentage of chocolate milk consumed during the test session relative to total fluid consumed during this period.

All individual group comparisons were evaluated with a Fisher test (Keppel, 1982), and all statistical differences were considered to be significant at the .05 level.

\section{Results and Discussion}

No differences in consumption were found during conditioning. The mean consumption for Groups T, OT, and $C$ was 3.8, 3.9, and $4.4 \mathrm{ml}$, respectively. Mean chocolate milk preferences during the retention test are presented in Figure 1. Differences in preference strength can be seen across conditioning experience and retention interval. A conditioning experience $\times$ retention interval analysis of variance was performed on these data. Significant main effects appeared for conditioning experience $[F(2,54)=52.1]$ and retention interval $[F(1,54)=14.5]$.

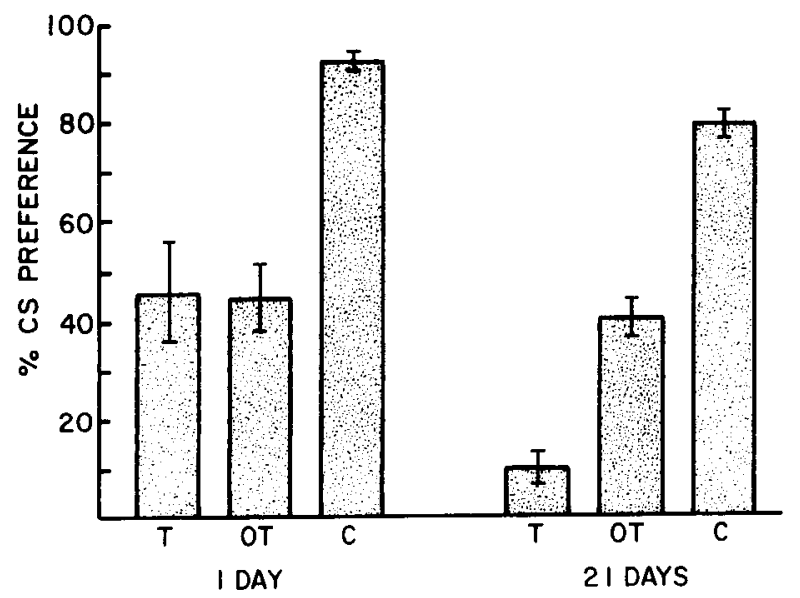

Figure 1. Percent chocolate milk preferences of weanlings in Experiment 1.
The interaction between these factors was also significant $[F(2,54)=3.5]$.

Individual group comparisons revealed that chocolate milk preferences for weanlings tested at the 1-day interval were significantly lower in Groups $\mathrm{T}$ and OT than in Group $\mathrm{C}$, and preferences in the former two groups were equivalent. This indicates conditioning but neither overshadowing or potentiation. At the 21-day interval, preferences in Group $\mathrm{T}$ were significantly lower than in Groups OT and C, and preferences were lower in Group OT than in Group C. This effect seemed to be due, however, to a surprising increase in retention over this 21-day interval among rats in Group $T$.

These results indicate that after a 1-day retention interval, odor had no attenuating effect on a conditioned taste aversion in weanlings, unlike the clear attenuation of taste aversion observed in adults under these conditions. This replicates the findings of Kraemer, Lariviere, and Spear (1988) and the general form of those found by Kucharski and Spear in several experiments (Spear \& Kucharski, 1984a, 1984b; Spear, 1984). After a 21-day retention interval, the attenuating effect of odor was no longer evident, as was found for adults by Kraemer, Lariviere, and Spear (1988) with a slightly different test.

Taste aversions in weanlings conditioned with taste alone unexpectedly increased over this 21-day period, whereas weanlings conditioned with an odor-taste compound showed no change in magnitude of their taste aversion over the same interval. The primary effect of the retention interval was to enhance the expression of conditioning to the chocolate milk when it was presented alone as a single-component CS. This effect was tested further in Experiment 2.

\section{EXPERIMENT 2}

The enhancement of aversion strength over a 21-day interval found in weanlings in Experiment 1 represents an "incubation" or "reminiscence" effect; an improvement was found in learned performance over a retention interval, rather than the more conventional decline (Spear, 1978). Whatever the actual mechanism, it is clear that weanlings' expression of a taste aversion can improve over time. One possible explanation for this effect is that retrieval or expression mechanisms themselves may improve with age. Perhaps the weanlings' initial aversions were weak, and over the extended retention interval improved mechanisms of expression allowed the weanlings to manifest a stronger avoidance response than occurred after the shorter interval. This explanation would predict that the manifest strength of taste aversions in younger animals should generally increase over time. This idea seems to be inconsistent with the more rapid forgetting of taste aversions that has been found in other studies with young rats (Schweitzer \& Green, 1982; Steinert, Infurna, \& Spear, 1980). It should be noted, however, that in these studies the aversions were relatively strong when tested after a short retention interval. It remains possible that when the expressed aversion is initially weak, as was the 
case in Experiment 1, the magnitude of an expressed aversion may increase over time.

Another possibility is that the relatively weak aversions found in weanlings tested after the 1-day interval represent an implicit flavor preexposure effect. Perhaps the chocolate milk was sufficiently similar to mother's milk that the memory of mother's milk disrupted the retrieval of the memory for the conditioning episode, as apparently occurs in the common effect of latent inhibition (Kraemer, Hoffmann, \& Spear, 1988; Kraemer \& Roberts, 1984). Such a retrieval deficit could have produced an attenuation of aversion strength after the 1-day interval. Over 21 days, forgetting of the memory for mother's milk could have rendered more effective the retrieval of the chocolate milk aversion. This in turn could have increased the tendency for aversions to be expressed. Such a mechanism has been suggested to account for the finding that flavor preexposure effects in adults decrease over relatively long retention intervals. (Kraemer \& Ossenkopp, 1986; Kraemer \& Roberts, 1984). The finding of stronger chocolate milk aversions in adults than in weanlings after the shorter interval (Kraemer, Lariviere, \& Spear, 1988 ) is consistent with the notion that these older rats had undergone sufficient forgetting of their prior experience with mother's milk.

If in younger rats the expression of relatively weak aversions increases with age, then any taste aversion found to be weak after a short retention interval should increase in strength over an extended retention interval, regardless of the nature of the taste involved. Alternatively, if an implicit taste preexposure effect is involved, then temporally based increases in aversion strength should be taste specific, and should not be simply a result of the magnitude of the initial aversion.

In Experiment 2 we tested taste aversions in weanlings after short and long retention intervals for each of three conditioning experiences. One group was exposed to chocolate milk paired with $.3 \mathrm{M} \mathrm{LiCl}$, another group was given saccharin paired with $.3 \mathrm{M} \mathrm{LiCl}$, and a third group received saccharin paired with $.15 \mathrm{M} \mathrm{LiCl}$. The difference in unconditioned-stimulus (US) intensity, as manipulated by variation in the molarity of the $\mathrm{LiCl}$, was designed to produce weaker saccharin aversions in the $.15 \mathrm{M}$ group than in the $.3 \mathrm{M}$ group. If younger animals generally improve at expressing weaker aversions after longer retention intervals, then it would be expected that a greater increase in aversion strength over a 21-day retention interval would be found in weanlings conditioned with the less intense $\mathrm{LiCl}$, that is, in the group given .15 M LiCl. Alternatively, if the incubation effect is taste specific and is not primarily a function of initial aversion strength, then expressed aversion magnitude would be expected to increase only in the group given chocolate milk as the CS, and aversion strength would be expected either to remain unchanged or to decrease in the groups conditioned with saccharin.

\section{Method}

The method was the same as that used in Experiment 1 except for the specific conditioning treatments. Sixty male and female wean- lings were randomly divided into six groups $(n=10)$. (Two of the weanlings in Group $S W-1$ died prior to testing and were not replaced, yielding 8 subjects in that group.) The $S W$ groups received a . $15 \%$ saccharin solution CS paired with a weak US (.15 M LiCl); the $\mathrm{CM}$ groups received chocolate milk paired with an injection of $.3 \mathrm{M} \mathrm{LiCl}$; the $\mathrm{SS}$ groups received a .15\% saccharin solution CS paired with a strong US ( $.3 \mathrm{M} \mathrm{LiCl})$. Testing occurred either 1 day (Groups CM-1, SW-1, and SS-1) or 21 days (Groups CM21, SW-21, and SS-21) after conditioning. A two-bottle preference test was administered, and flavor preference scores were calculated for each subject.

\section{Results and Discussion}

The mean amounts of liquid consumed during conditioning by groups given chocolate milk, saccharin paired with $.15 \mathrm{M} \mathrm{LiCl}$, and saccharin paired with $.3 \mathrm{M} \mathrm{LiCl}$ were $2.8,1.8$, and 1.92 , respectively; these means differ significantly $[F(2,57)=13.16]$. The weanlings conditioned with chocolate milk consumed more on the conditioning day than did those conditioned with saccharin, and the two groups given saccharin drank equivalent amounts.

Mean CS preferences are presented in Figure 2. The preferences of weanlings in the three conditioning treatments differed at the 1-day retention interval but were very similar at the 21-day retention interval. A conditioning treatment $\times$ retention interval analysis of variance revealed a significant interaction between these two factors $[F(1,54)=3.8]$. Analyses of main effects confirmed that preferences differed significantly at the 1-day interval but not at the 21-day interval. At the 1-day interval, preferences in Groups CM-1 and SW-1 were equivalent but significantly higher than those in Group SS-1. Because the $\mathrm{CM}$ and SW groups shared weakness of conditioned aversion but differed in the quality of tastes used as CSs, an increase in retention of aversion by Group CM-21 but not by Group SW-21 would indicate that taste quality of the CS was the more important factor for this effect.

Preference for chocolate milk was indeed significantly lower in Group CM-21 than in Group CM-1, replicating the results of Experiment 1. Preference in Groups SW21 and SS-21 was not significantly lower than preference in Groups SW-1 and SS-1. There was, in contrast, a trend

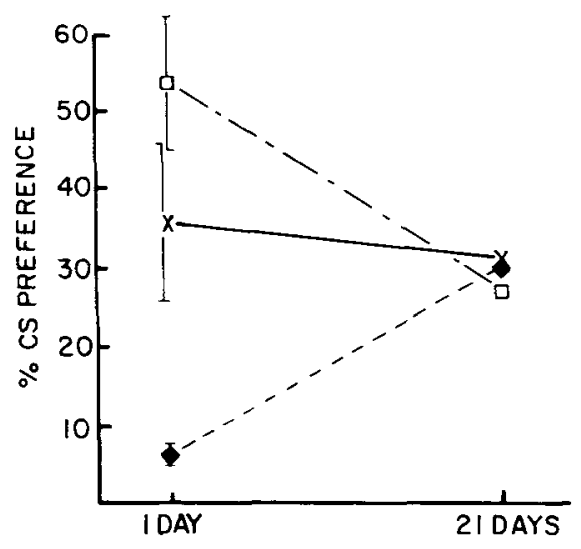

Figure 2. Percent taste preferences for weanlings in Experiment 2

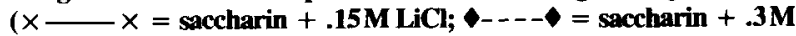
LiCl; $\square---\square=$ chocolate milk $+.3 \mathrm{M} \mathrm{LiCl})$. 
in Group SS-21 toward forgetting; this effect was opposite that for animals given chocolate milk paired with $\mathrm{LiCl}$.

These results replicate the findings of Experiment 1 in showing that chocolate milk aversions in weanlings increase in strength over a 21-day interval. This effect does not appear to be a result of a general tendency for expressed aversion to strengthen over time. Weanlings given saccharin gave no indication of such an effect. These results are more compatible with the flavor preexposure hypothesis than with the notion that expression of weak aversions by weanlings generally tends to improve over time.

\section{GENERAL DISCUSSION}

The present experiments revealed an interesting influence of retention interval on taste aversions in weanlings. At this age, manifest aversion strength increased over an extended interval in animals conditioned with taste alone, but not in animals conditioned with odor-taste compounds. This effect of retention interval in weanlings was essentially opposite that reported for the same tests with adults (Kraemer, Lariviere, \& Spear, 1988). Experiment 2 further revealed that this effect does not generally occur whenever initial aversion strength is relatively weak; it seems to be taste specific. Although chocolate milk aversions found to be relatively weak in animals tested after a 1-day interval were found to be stronger in animals tested after 21 days, no such change in aversion strength was noted in animals that expressed comparably weak saccharin aversions at the short interval.

It is possible that experiences prior to or after the conditioning episode, or both, are responsible for this effect. For example, it has been found that nursing-related taste aversions are affected by the young animal's experience with solid food. Specifically, taste aversions conditioned while nursing are more readily expressed in animals that have had experience with solid food, either before or after conditioning (Gubernick \& Alberts, 1986). In the present case, weanlings tested after 21 days would have had much more exposure to solid food, and this experience could have affected expression of a previously established taste aversion. Alternatively, the weanlings' experience with mother's milk could have produced an implicit preexposure effect. According to this hypothesis, the memory for mother's milk interfered with the effective retrieval of the weanlings' memory for the conditioning episode when testing occurred after the short retention interval. After the prolonged interval, forgetting of the memory for mother's milk resulted in more effective retrieval of the conditioned aversion, yielding stronger expressed aversions. This explanation resembles that proposed to account for the dissipation in the attenuating effects of flavor preexposure found in adults tested after an extended retention interval (Kraemer \& Roberts, 1984).

It should be emphasized that whatever the ultimate mechanism for this effect, a successful explanation will need to address the finding that for these weanlings, taste aversions conditioned in compound with an odor failed to increase over the retention interval. Also important from an ontogenetic perspective is the finding that the pattern of results for weanlings tested after 21 days mirrors the pattern observed for adults tested after 1 day (Kraemer, Lariviere, \& Spear, 1988). It may be that the extended retention interval provides time for the weanlings' expression mechanisms to mature so that they behave as adults. The question would then remain, Why should the weanlings behave like adults tested after a short interval, instead of like adults tested after a prolonged interval? Clearly, further investigation is needed to clarify the role of retention interval in conditioned taste aversions in both weanlings and adults.

\section{REFERENCES}

Gubernick, D. J., \& AlberTs, J. R. (1986). A specialization of taste aversion learning during suckling and its weaning-associated transformation. Developmental Psychology, 17, 613-628.

Kasprow, W. J., Cacheiro, H., Balaz, M. A., \& Miller, R.R. (1982). Reminder-induced recovery of associations to an overshadowed stimulus. Learning \& Motivation, 13, 155-166.

Kaufman, M. A., \& Bolles, R. C. (1981). A nonassociative aspect of overshadowing. Bulletin of the Psychonomic Society, 18, 319-320.

KEPPEL, G. (1982). Design and analysis: A researcher's handbook (2nd ed.). Englewood Cliffs, NJ: Prentice-Hall.

Kraemer, P. J., Hoffmann, H., \& Spear, N. E. (1988). Attenuation of the CS-preexposure effect after a retention interval in preweanling rats. Animal Learning \& Behavior, 16, 185-190.

Kraemer, P. J., Lariviere, N. A., Spear, N. E. (1988). Expression of a taste aversion conditioned with an odor-taste compound: Overshadowing is relatively weak in weanlings and decreases over a retention interval $\mathrm{n}$ adults. Animal Learning \& Behavior, 16, 164-168.

Kraemer, P. J., \& Roberts, W. A. (1984). The influence of flavor preexposure and test interval on conditioned taste aversions in the rat. Learning \& Motivation, 15, 259-278.

KRAEMER, P. J., \& OsSEnKOPP, K.-P. (1986). The effects of flavor preexposure and test interval on conditioned taste aversions in rats. Bulletin of the Psychonomic Society, 24, 219-221.

SCHWErTzer, L. \& GreEN, L. (1982). Acquisition and extended retention of a conditioned taste aversion in preweanling rats. Journal of Comparative \& Physiological Psychology, 96, 791-806.

SMITH, G. J., \& SPEAR, N. E. (1981). Role of proactive interference in infantile forgetting. Animal Learning \& Behavior, 9, 371-380.

SPEAR, N. E. (1978). The processing of memories: Forgetting and retention. Hillsdale, NJ: Erlbaum.

SPEAR, N. E. (1981). Extending the domain of memory retrieval. In N. E. Spear \& R. R. Miller (Eds.), Information processing in animals: Memory mechanisms (pp. 341-378). Hillsdale, NJ: Erlbaum.

SPEAR, N. E. (1984). Ecologically determined dispositions control the ontogeny of learning and memory. In R. Kail \& N. E. Spear (Eds.), Comparative perspectives on the development of memory (pp. 325358). Hillsdale, NJ: Erlbaum.

SPEAR, N. E., \& KUCharsKI, D. (1984a). Ontogenetic differences in stimulus selection during conditioning. In R. V. Kail \& N. E. Spear (Eds.), Memory development: Comparative perspectives (pp. 227-252). Hillsdale, NJ: Erlbaum.

SPEAR, N. E., KucharSKI, D. (1984b). Ontogenetic differences in the processing of multi-element stimuli: Potentiation and overshadowing. In H. Roitblat, T. Bever, \& H. Terrace (Eds.), Animal cognition (pp. 545-568). Hillsdale, NJ: Erlbaum.

Steinert, P. A., Infurna, R. N., \& SPEAR, N. E. (1980). Long-term retention of a conditioned taste aversion in preweanling and adult rats. Animal Learning \& Behavior, 8, 375-381.

(Manuscript received April 10, 1987; revision accepted for publication September 22, 1987.) 